\title{
Family Physicians' Beliefs about Genetic Contributions to Racial/Ethnic and Gender Differences in Health and Clinical Decision-Making
}

\author{
Esther Warshauer-Baker Vence L. Bonham Jean Jenkins Nancy Stevens \\ Zintesia Page Adebola Odunlami Colleen M. McBride \\ Social and Behavioral Research Branch, National Human Genome Research Institute, National Institutes of Health, \\ Bethesda, Md., USA
}

\section{Key Words}

Genetics · Race - Ethnicity · Gender • Clinical practice • Health disparities

\begin{abstract}
Greater attention towards genetics as a contributor to group health differences may lead to inappropriate use of race/ ethnicity and gender as genetic heuristics and exacerbate health disparities. As part of a web-based survey, 1,035 family physicians (FPs) rated the contribution of genetics and environment to racial/ethnic and gender differences in health outcomes, and the importance of race/ethnicity and gender in their clinical decision-making. FPs attributed racial/ethnic and gender differences in health outcomes equally to environment and genetics. These beliefs were not associated with rated importance of race/ethnicity or gender in clinical decision-making. FPs appreciate the complexity of genetic and environmental influences on health differences by race/ethnicity and gender.

Copyright $\odot 2008$ S. Karger AG, Basel
\end{abstract}

\section{Introduction}

Recent advances in genomics [1-4] have generated controversy over the relative roles of genetics and environment in explaining why some groups experience poorer health outcomes than others. In particular, concern has been raised that research highlighting genetic differences among racial/ethnic [5] groups and linking those differences to health outcomes may encourage health care providers to use race/ethnicity in ways that exacerbate health disparities [6-9]. Similarly, the recent sequencing of the $\mathrm{X}$ chromosome has led to new insights and speculation regarding its role in gender differences in health outcomes $[10,11]$ and the extent to which providers should use gender as a heuristic in clinical care.

In this ongoing debate, some have argued that research on genetic variation among subgroups will lead to better understandings of health differences $[12,13]$ that in turn can be used to customize clinical practice in ways that improve health outcomes for all $[14,15]$. Others have expressed concern that these investigations foster deterministic thinking and encourage 'profiling', in which the clinical significance of between-group genetic variation is overemphasized $[16,17]$. Meanwhile, researchers have investigated physicians' implicit, or unconscious, use of

\section{KARGER \\ Fax +4161306 1234 \\ E-Mail karger@karger.ch}

www.karger.com
(C) 2008 S. Karger AG, Basel

1422-2795/08/0116-0352\$24.50/0

Accessible online at:

www.karger.com/cmg
Colleen M. McBride, $\mathrm{PhD}$

Social and Behavioral Research Branch

National Human Genome Research Institute, NIH

31 Center Drive, Bldg 31, Room B1 B54B, Bethesda, MD 20892-0249 (USA)

Tel. +1 301594 6788, Fax +1 301480 3108, E-Mail cmcbride@mail.nih.gov 
race and gender in clinical decision-making and its impact on clinical care quality and health outcomes [18-22]. However, there is little empirical data to inform the controversy over the explicit, or deliberate, use of race/ethnicity and gender as clinical heuristics and further, how genomic discoveries might influence use of these heuristics $[9,23-26]$.

The beliefs and practices of family physicians (FPs) will play a critical role in shaping how genomic discovery is applied in clinical care. FPs comprise the largest physician group in the US and provide the usual source of care for the majority of Americans [27]. Nearly 1 in 4 of all office visits in the US are made to general and family practitioners every year [28]. More so than any other physician group, FPs are well dispersed geographically throughout the US parallel to the general population [29]. Moreover, family practice is the specialty group that treats most common diseases in patients of all ages.

In anticipation that the controversies related to genetics and health differences will continue and evolve, we conducted a web-based survey of a sample of FPs to evaluate current beliefs and clinical practices related to genetics, race/ethnicity and gender. The specific objective of the survey was to gain insight into 2 questions: (1) to what extent do FPs believe race/ethnicity and gender differences in health outcomes are due to genetics and environment, and (2) are FPs' beliefs about the relative contributions of genetics and environment to health differences associated with the importance they place on race/ethnicity and gender in their clinical decision-making?

\section{Methods}

\section{Sample}

Subjects were recruited from the membership records of the American Academy of Family Physicians (AAFP), the national association of family doctors. The AAFP is one of the largest national medical organizations, with more than 94,000 members in 50 states, D.C., Puerto Rico, the Virgin Islands and Guam.

\section{Study Design and Survey Administration}

In January 2005, as part of implementation of the AAFP's Annual Clinical Focus on Genomics, a sample of 10,000 AAFP members were selected using random sampling techniques. A stratified sample was drawn such that half of the sample had completed residency less than 15 years ago. The sampled members were sent invitation e-mails from the AAFP that described the study's purpose, the risks and benefits of participating, and provided participants a URL to access the web-based survey. The 30 -min survey was available online for 3 weeks. As an incentive to participate, FPs who completed the survey were entered in a lottery to win 1 of 6 iPods. Invitations were sent in 2 groups of 5,000 members each; the first group was sent on January 3, 2005 and the second group was sent on January 20,2005. The entire group was sent 2 reminder e-mails within 2 weeks after the original invitations.

\section{Survey Content}

FPs were asked about their beliefs regarding the relative importance of genetics and environment for differences in health outcomes using 2 scenarios that depicted well-publicized health differences. One scenario depicted a circumstance of racial/ethnic difference, while the other depicted one of gender difference. The scenarios were presented as follows.

Scenario 1: 'Racial/ethnic differences in health outcomes are well documented in the U.S. For example, white women are more likely to be diagnosed with breast cancer than black women, but black women are more likely to die from breast cancer than white women. However, the causes for these differences are currently not well understood.'

Scenario 2: 'Gender differences in health outcomes are also well documented. For example, for heart disease, there are marked differences between men and women in the age of incidence and the location and manifestation of plaques in the arteries.'

All FPs were presented with both scenarios. After each scenario, FPs were asked to rate on 7-point scales ( 1 = genetics; $4=$ equally attributable; 7 = environment): 'To what extent do you think genetics and the environment contribute to these differences?' They also were asked to rate the importance of race/ethnicity and gender as well as several other factors in their clinical decision-making with the following question: 'Thinking about how you make clinical decisions (such as which drug to prescribe), to what extent do you think each of the following is important to consider?' Family history, age, gender, insurance status and race/ ethnicity were presented, each accompanied by 7-point scales ( 1 = not important at all; 7 = essential).

Other relevant characteristics assessed in the survey included characteristics of the practice setting, time spent in research and with patients and self-identified race (FPs were asked to choose from 1 or more of 6 options, namely the 5 racial categories used by the Office of Management and Budget and 'other'). We acquired the physicians' gender and years since residency through the AAFP membership database. Because clinical applications of genomics related to primary care practice are in nascent stages, we also assessed FPs' affinity towards incorporating new ideas into their clinical practice with 11 questions from an approach to work scale [29]. Factor analysis, using an oblique promax rotation method, revealed 2 latent factors underlying the responses. These 2 latent factors each had eigenvalues greater than 1 and a small negative correlation with one another (Spearman correlation: $-0.19)$. The 2 factors were easily interpretable and were labeled 'innovative approach' (for example, 'I like to implement new ideas') and 'structured approach' (for example, 'I prefer to work in a traditional setting'). Scale scores, created by summing up the items that loaded onto each factor, had high internal reliability (Cronbach's $\alpha$ : 0.88 and 0.80 , respectively).

\section{Analysis}

We computed means and proportions to describe the distribution of survey items. Pearson correlation coefficients were generated to test the associations among these survey items. Using multivariate regression models, we tested the association of 9 dichot- 
Table 1. Characteristics of survey respondents $(\mathrm{n}=994)$

\begin{tabular}{lc}
\hline Male & $67(668)$ \\
Race & $79(937)$ \\
$\quad$ White & $7(67)$ \\
Asian & $4(39)$ \\
Hispanic & $3(24)$ \\
$\quad$ Black & $3(29)$ \\
Other & $4(35)$ \\
$\quad$ Not specified & $29(269)$ \\
Working in teaching/training environment & $45(448)$ \\
>15 years since residency & $61(559)$ \\
Innovative approach to work ${ }^{1}$ & $51(468)$ \\
Structured approach to work ${ }^{1}$ & \\
Practice environment & \\
$\quad$ Urban & $66(581)$ \\
$\quad>15 \%$ nonwhite residents & $52(444)$ \\
$\quad>10 \%$ residents in poverty & $46(389)$ \\
\hline
\end{tabular}

Figures are percentages with numbers in parentheses.

${ }^{1}$ Often or most of the time. ${ }^{2}$ Indicated by zip code.

omous physician characteristics and all 2 -way interactions among them, with responses first to the 2 health differences questions (gene environment contributions to racial/ethnic and gender differences) and second to the importance of race/ethnicity and gender to clinical decision-making. The 9 physician characteristics were: male versus female; university, teaching and residency setting versus not; urban versus nonurban practice setting; zip code of practice with $>10 \%$ poverty versus not; zip code of practice with $>15 \%$ nonwhite residents versus not; $>15$ years since residency completion versus not; $>50 \%$ of time spent seeing patients versus not; innovative versus not; prefer structure versus not. Throughout this report, $\mathrm{p}<0.05$ was used as the criterion for statistical significance. The demographics of practice setting were based on FPs' reports of the zip code of practice. The zip codes were linked to the 2000 census data and coded for the percentage of nonwhite residents and the percentage of population below poverty level. We based the cut points for each at the median value within our sample. We created an indicator variable that for example took the value 1 if the physician's practice was in a zip code with more than $15 \%$ nonwhite residents and the value 0 otherwise.

\section{Results}

\section{Participation}

A total of 1,035 FPs completed the web-based survey, representing a response rate of $10 \%$. Using AAFP membership data, we were able to compare those who did and did not respond on several demographic characteristics. The only difference of significance was that respondents who were involved in research were overrepresented in the sample compared to the AAFP membership as a whole (18 vs. 9\%).

For this report, FPs who reported spending $10 \%$ or less of their time with patients were excluded to confine analyses to participants who were active care providers. The final sample includes 944 FPs. Characteristics of these respondents are shown in table 1 . The majority of FPs who completed the survey were male (67\%), white (79\%), practiced in urban areas $(66 \%)$ and reported an innovative approach to work (61\%). About half of the participants reported practicing in a clinic in which $>15 \%$ of patients were from a minority group and where $>10 \%$ of patients lived in poverty.

\section{Perceived Contribution of Genetics and Environment to Racial/Ethnic and Gender Differences in Health Outcomes}

Generally, FPs reported that racial/ethnic differences in health outcomes were equally due to genetics and environment. On the 7 -point scale ( 1 = genetics; 4 = equally attributable; 7 = environment), FPs rated racial/ethnic differences in health outcomes as only slightly more due to environment than genetics $[$ mean $=4.6(\mathrm{SD}=1.2)$, where 4 is equally attributable]. By comparison, FPs rated gender differences in health outcomes as only slightly more due to genetics than environment $[$ mean $=3.6$ $(\mathrm{SD}=1.3)$, where 4 is equally attributable]. Very few FPs attributed racial/ethnic or gender differences entirely to genetics ( $<1$ and $2.6 \%$, respectively) or to environment (3.5 and $<1 \%$, respectively; table 2 ).

We used a paired t test to assess the equality of means for the 2 items. The null hypothesis of equal means was rejected ( $p<0.001$ ), indicating that FPs were significantly more likely to attribute gender differences in health outcomes to genetics than racial/ethnic differences. In addition, there was a small but significant correlation ( $r=0.20, p<0.0001)$ between FPs' beliefs about the contribution of genetics to racial/ethnic differences and gender differences in health outcomes. Those who rated genetics as a stronger contributor to racial/ethnic differences were inclined to do the same for gender differences (table 3).

In multivariate analyses of FP characteristics with racial/ethnic differences, we found that FPs who practiced in teaching settings and FPs who were more innovative in their practice approach rated genetics as contributing less to racial/ethnic differences in health outcomes than their peers (teaching vs. non-teaching: model means, 4.69 vs. $4.49, \mathrm{p}=0.02$; more innovative vs. less innovative: model means, 4.69 vs. $4.48, \mathrm{p}=0.01)$. For health outcome 
Table 2. Beliefs about contributors to racial/ethnic and gender differences in health outcomes

\begin{tabular}{|c|c|c|c|c|c|c|c|c|}
\hline & \multirow[t]{2}{*}{ Mean rating ${ }^{1}$} & \multicolumn{7}{|c|}{ Respondents $^{2}$} \\
\hline & & 1 & 2 & 3 & 4 & 5 & 6 & 7 \\
\hline Gender & $3.64(1.3)$ & $2.6(24)$ & $17.8(163)$ & $25.2(231)$ & $30.9(283)$ & 15 (138) & $7.7(71)$ & $0.76(7)$ \\
\hline Race/ethnicity & $4.57(1.2)$ & $0.3(3)$ & $3.3(30)$ & $13.0(119)$ & $36.3(334)$ & $20.6(189)$ & $23.0(212)$ & $3.5(32)$ \\
\hline
\end{tabular}

${ }^{1}$ Figures in parentheses are SD.

${ }^{2}$ Figures are percentages with numbers in parentheses. Numbers do not add up to 994, since each question had some missing values.

Table 3. Pearson correlation coefficients for beliefs and clinical decision-making

\begin{tabular}{|c|c|c|c|c|c|c|c|c|}
\hline 1 & Extent genetics contributes to race/ethnicity differences & 1.0 & $0.20^{* * *}$ & $-0.10^{* *}$ & -0.01 & -0.04 & $0.06^{*}$ & -0.05 \\
\hline 2 & Extent genetics contributes to gender differences & & 1.0 & 0.02 & $-0.07^{*}$ & 0.01 & -0.03 & 0.03 \\
\hline 3 & Family history important to clinical decisions & & & 1.0 & $0.31^{* * *}$ & $0.43^{* * *}$ & $-0.11^{* * *}$ & $0.39^{* * *}$ \\
\hline 4 & Age important to clinical decisions & & & & 1.0 & $0.45^{* * *}$ & $0.07^{*}$ & $0.34^{* * *}$ \\
\hline 5 & Gender important to clinical decisions & & & & & 1.0 & -0.01 & $0.53^{* * *}$ \\
\hline
\end{tabular}

${ }^{*} \mathrm{p}<0.05 ;{ }^{* *} \mathrm{p}<0.01 ;{ }^{* *} \mathrm{p}<0.001$.

differences by gender, we found that compared to their peers, FPs who had completed their residencies $\leq 15$ years ago and those who spent $\leq 50 \%$ of their time with patients attributed gender differences less to genetics than environment $(>15$ years vs. $\leq 15$ years: model means, 3.56 vs. $3.90, \mathrm{p}=0.01 ;>50 \%$ time with patients vs. $\leq 50 \%$ : model means, 3.60 vs. $3.87, \mathrm{p}=0.007)$.

\section{Perceived Importance of Race/Ethnicity and}

Gender in Clinical Decision-Making

FPs rated age as being most important in making their clinical decisions, with a mean rating of 5.9 on the 7-point scale ( 1 = 'not at all important'; 7 = 'essential'). Gender was given the next highest rating of importance, followed by race/ethnicity and family history $(4.6,4.4$ and 4.4 , respectively). Insurance status was given the lowest rating of importance, at 4.3. Less than one third of FPs viewed gender or race/ethnicity as essential to clinical decisionmaking (27\% rated 6 or 7 on the 7-point scale). Similarly, only $24 \%$ viewed family history as essential (table 4 ).

FPs who rated race/ethnicity as more important in their clinical decision-making were more likely to do the same for gender $(r=0.53, p<0.0001)$. FPs who rated age as more important in clinical decision-making also were likely to rate gender and race/ethnicity as more important $(\mathrm{r}=0.45$ and 0.34 , respectively, both $\mathrm{p}<0.001)$. Additionally, those who rated gender or race/ethnicity as more important were likely to rate family history as more important to their clinical decisions $(r=0.43$ and 0.39 , respectively, both $\mathrm{p}<0.001$ ).

There were other statistically significant correlations among FPs' ratings of the importance of the various factors in clinical decision-making as well as among FP' ratings on the extent genetics contributes to differences by race/ethnicity and gender (table 3 ).

In multivariate analyses of the importance of race/ethnicity on clinical decisions, we found that females, FPs who practiced in urban environments or in areas with $>10 \%$ poverty, those who were $>15$ years out of residency or who self-reported to be more innovative in their practice approach, each placed more importance on race/ethnicity than their peers (female vs. male: model means, 4.46 vs. $4.19, \mathrm{p}=0.01$; urban vs. nonurban: model means, 4.47 vs. $4.18, \mathrm{p}=0.008 ;>10 \%$ poverty vs. $\leq 10 \%$ poverty: model means, 4.49 vs. $4.16, \mathrm{p}=0.001 ;>15$ years since residency vs. $\leq 15$ years: model means, 4.47 vs. $4.18, \mathrm{p}=$ 
Table 4. Importance of patient characteristics for clinical decision-making $(\mathrm{n}=994)$

\begin{tabular}{|c|c|c|c|c|c|c|c|c|}
\hline & \multirow[t]{2}{*}{ Mean rating ${ }^{1}$} & \multicolumn{7}{|c|}{ Respondents $^{2}$} \\
\hline & & 1 & 2 & 3 & 4 & 5 & 6 & 7 \\
\hline Age & $5.86(1.1)$ & $0.1(1)$ & $0.4(4)$ & $2.2(21)$ & $7.6(73)$ & $24.0(230)$ & $32.3(310)$ & $33.4(321)$ \\
\hline Gender & $4.61(1.5)$ & $1.6(15)$ & $8.5(81)$ & $11.5(110)$ & $22.9(219)$ & $27.9(267)$ & $16.2(155)$ & $11.4(109)$ \\
\hline Race/ethnicity & $4.42(1.4)$ & $1.9(18)$ & $8.2(79)$ & $16.1(154)$ & $24.4(234)$ & $26.8(256)$ & 14.5 (139) & $8.0(77)$ \\
\hline Family history & $4.39(1.5)$ & $2.2(21)$ & $11.6(111)$ & $15.1(145)$ & $21.7(208)$ & $25.5(245)$ & $13.8(133)$ & $10.1(97)$ \\
\hline Insurance & $4.27(1.7)$ & $8.0(77)$ & $11.7(112)$ & $10.7(103)$ & $21.0(202)$ & $21.4(205)$ & $17.8(171)$ & $9.4(90)$ \\
\hline
\end{tabular}

${ }^{1}$ Figures in parentheses are SD.

${ }^{2}$ Figures are percentages with numbers in parentheses. Numbers do not add up to 994, since each question had some missing values.

0.005 ; innovative vs. not innovative: model means, 4.44 vs. $4.21, \mathrm{p}=0.002)$.

For importance of gender in clinical decision-making, females and FPs who were $>15$ years from residency rated gender as more important than their peers (female vs. male: model means, 4.74 vs. $4.46, p=0.006 ;>15$ years since residency vs. $\leq 15$ years: 4.75 vs. $4.45, \mathrm{p}=0.003)$.

Association of Attributions of Health Differences to Genetics and Ratings of Importance of Race/Ethnicity and Gender in Clinical Decisions

FPs' beliefs about the relative contribution of genetics and environment to differences in health outcomes were not correlated with their ratings of the importance of race/ethnicity $(r=-0.05)$ or gender $(r=0.01)$ in clinical decision-making (table 3 ).

\section{Discussion}

The FPs who completed our survey attributed racial/ ethnic differences slightly more to environment and gender differences slightly more to genetics. FPs' views about the etiology of racial/ethnic and gender differences in health were strongly and positively correlated. However, the proportion of FPs who strongly endorsed either genetics or environment as the sole cause of health differences was quite low, suggesting that the vast majority of FPs appreciate that common conditions are etiologically complex.

FPs who were practicing in teaching environments, those who reported being more in novative and those who were younger were less inclined to attribute health differences to genetics. These results may reflect these physicians' more recent and/or greater exposure to genetic curricula that increasingly acknowledges growing scientific evidence for the complex influences of environment and genetics on health outcomes.

While our data show that the FPs surveyed view race/ ethnicity and gender as providing clinically relevant information, relatively few of the physicians in our sample rated gender or race/ethnicity as essential to clinical decision-making. Moreover, our results suggest that FPs who regard race/ethnicity and gender as important in making their clinical decisions are not more likely than their peers to view race/ethnicity or gender as proxies for genetic differences. Our data reveal positive correlations between practice environment (that is, urban areas and areas with $>10 \%$ poverty) and FPs' ratings of the importance of race/ ethnicity in clinical decisions. Further research is needed to better understand these relationships.

Not surprisingly, our results indicated that FPs consider multiple patient characteristics when making their clinical decisions. However, given the widely acknowledged importance of family history as a tool for ascertaining clinically relevant genetic, environmental and psychosocial factors [30-32], it was surprising that FPs rated the importance of family history as no more important than race/ethnicity and gender in their clinical decision-making. It is possible that the time and effort required to collect and update family history offsets some of its value as a clinical tool, particularly if one considers the ever increasing number of things that FPs are expected to do as part of routine clinic visits [33]. Race/ethnicity and gender may be viewed as quick, albeit imprecise, indicators of medically relevant genetic, environmental and psychosocial factors. The evaluation of recent efforts by the Surgeon General and others to foster widespread adoption of more rigorous family history taking, as well as the development and evaluation of new, modified ver- 
sions of family history tools [34], may help give information about what is needed to improve the perceived clinical utility of family history.

Lastly, although not a primary focus of this study, our results raise questions about physicians' attitudes regarding insurance status that could be explored in future research. Insurance status was rated as least important of all the characteristics, though still more important than not, and these ratings were not correlated with ratings of the importance of other patient characteristics. Further research is needed to understand why and how physicians use insurance status in clinical decision-making, and how these practices might affect the quality of care for patients with no or poor insurance coverage.

Like any study, these results must be considered with some caveats. We developed our own single measures of perceptions about race/ethnicity and gender differences and the role of genes and environment. Questions assessed clinical decisions under the umbrella of nonspecific clinical decision-making. Race/ethnicity and gender may be more important for some clinical decisions [35, 36] than others. FPs' ratings of the importance of a given factor in their clinical decisions may not represent that factor's actual influence on decision-making, and would not capture physicians' implicit use of race/ethnicity and gender in their clinical decision-making. Previous research into the providers' contribution to health disparities suggests that patient race/ethnicity has an implicit, unconscious effect on FPs' clinical decision-making [18]. Questions regarding the importance of genetics and environment in health differences relied on the terms genetics and environment without defining either, leaving room for respondents to interpret them differently. Also, the scenario dealing with $\mathrm{racial} / \mathrm{ethnic}$ health differences described disease diagnosis and outcome, while the scenario dealing with gender health differences described disease incidence and clinical characteristics. This asymmetry may limit the comparability of FPs' responses to the 2 scenarios. Lastly, we recognize the limitation of combining race and ethnicity as one descriptor. Each term has different meanings that vary in use and construed meaning, and we cannot characterize how FPs interpreted the combined terminology. Future research should be conducted to refine measures of these constructs and to understand how the explicit beliefs studied here relate to the implicit influence of patient characteristics on physician behavior.

We cannot say whether FPs' ratings of the importance of race/ethnicity and gender are appropriate or inappropriate, nor can we say whether those who reported plac- ing substantial importance on these characteristics use them to their patients' benefit. Further research is needed to link these practices to meaningful clinical outcomes in order to gain understanding of their effects.

Our response rate of $10 \%$ was low. However, the 1,035 FPs who completed the survey were not notably different from the overall membership of the AAFP. Additionally, our sample was not sufficiently racially or ethnically diverse to use physician self-reported race/ethnicity as an analytic variable. This should be explored further; other studies querying FPs' beliefs about health differences have shown significant differences by FPs' self-identified race/ethnicity.

In conclusion, this study is among the first to provide empirical evidence of a large group of physicians' beliefs relevant to the current discussions about physicians' attitudes regarding race/ethnicity and gender in health outcomes and clinical decision-making. How these perceptions will evolve with the increasing availability of genetic susceptibility testing and pharmacogenomics, and how, if at all, these perceptions will shift and influence clinical decision-making is worth continued study if we are to better understand and shape integration of genomic medicine into primary care practice.

\section{Acknowledgement}

Funding for this study was provided by the Social and Behavioral Research Branch at the National Human Genome Research Institute of the National Institutes of Health.

References

1 Rosenberg NA, Pritchard JK, Weber JL, Cann HM, Kidd KK, Zhivotovsky LA, Feldman MW: Genetic structure of human populations. Science 2002;298:2381-2385.

2 Risch N, Burchard E, Ziv E, Tang H: Categorization of humans in biomedical research: genes, race and disease. Genome Biol 2002;3: $1-12$.

3 Jorgenson E, Tang H, Gadde M, Province M, Leppert M, Kardia S, Schork N, Cooper R, Rao DC, Boerwinkle E, Risch N: Ethnicity and human genetic linkage maps. Am J Hum Genet 2005;76:276-290.

4 Ross M, Grafham D, Coffey A, Scherer S, McLay K, Muzny D, Platzer M, Howell GR, Burrows C, Bird CP, Frankish A, Lovell FL, Howe KL, Ashurst JL, Fulton RS, Sudbrak R, Wen G, Jones MC, Hurles ME, Andrews TD, Scott CE, Searle S, Ramser J, Whittaker A, Deadman R, Carter NP, Hunt SE, Chen R, Cree A, Gunaratne P, Havlak P, Hodgson A et al: The DNA sequence of the human $\mathrm{X}$ chromosome. Nature 2005;434:325-337. 
5 Anderson MR, Moscou S, Fulchon C, Neuspiel DR: The role of race in the clinical presentation. Fam Med 2001;33:430-434.

-6 Lanfear DE, Marsh S, Cresci S, Shannon WD, Spertus JA, McLeod HL: Genotypes associated with myocardial infarction risk are more common in African Americans than in European Americans. J Am Coll Cardiol 2004:44:165-167.

7 Burchard EG, Ziv E, Coyle N, Gomez SL, Tang H, Karter AJ, Mountain JL, Perez-Stable EJ, Sheppard D, Risch N: The importance of race and ethnic background in biomedical research and clinical practice. N Engl J Med 2003;348:1170-1175.

-8 Feldman MW, Lewontin RC, King MC: Race: a genetic melting-pot. Nature 2003;424:374.

-9 Sankar P, Cho MK, Condit CM, Hunt LM, Koenig B, Marshall P, Lee SS, Spicer P: Genetic research and health disparities. JAMA 2004;291:2985-2989.

10 Check E: The X factor. Nature 2005;434:266267.

11 Guterl F: The truth about gender. MSNBC. com, March 28. http://msnbc.msn.com/id/ 7243350/site/newsweek. Accessed March 21, 2005.

12 Taylor AL, Wright JT: Should ethnicity serve as the basis for clinical trial design? Circulation 2005;112:3654-3660.

-13 Sinha M, Larkin EK, Elston RC, Redline S: Self-reported race and genetic admixture. N Engl J Med 2006;354:421-422.

14 Bamshad M: Genetics influence on health. JAMA 2005;249:937-946.

15 Need A, Motulsky A, Goldstein D: Priorities and standards in pharmacogenetics research. Nat Genet 2005;37:671-681.

16 Fine M, Ibrahim S, Thomas S: The role of race and genetics in health disparities research. Am J Public Health 2005;95:21252128.

17 Cooper RS, Kaufman JS, Ward R: Race and genomics. N Engl J Med 2003;348:11661170.
18 Van Ryn M: Research on the provider contribution to race/ethnicity disparities in medical care. Med Care 2002;40(suppl):I-140I-151.

19 Safran D, Rogers W, Tarlov A, McHorney C, Ware J Jr: Gender differences in medical treatment: the case of physician-prescribed activity restrictions. Soc Sci Med 1997;45: 711-722.

20 Betancourt JR, Green AR, Carrillo JE, Park ER: Cultural competence and health care disparities: key perspectives and trends. Health Aff 2005;24:499-505.

21 Schulman KA, Berlin JA, Harless W, Kerner JF, Sistrunk S, Gersh BJ, Dube R, Talaghani CK, Burke JE, Williams S, Eisenberg JM, Escarce JJ: The effect of race and sex on physicians' recommendations for cardiac catherization. N Engl J Med 1999;340:618-626.

22 Fincher C, Williams JE, MacLean V, Allison JJ, Kiefe CI, Canto J: Racial disparities in coronary heart disease: a sociological view of the medical literature on physician bias. Ethn Dis 2004;14:360-371.

23 Ota Wang V, Sue S: In the eye of the storm: race and genomics in research and practice. Am Psychol 2005;60:37-45.

24 Braun L: Race, ethnicity, and health: can genetics explain disparities? Perspect Biol Med 2002;45:159-174

25 Leroi AM: A family tree in every gene. NY Times, March 14, 2005, A23.

26 Summers LH: Remarks at NBER Conference on Diversifying the Science and Engineering Workforce. Cambridge, The Office of the President, Harvard University, 2005. http:// www.president.harvard.edu/speeches/2005/ nber.html (accessed March 13, 2005).

27 Medical Expenditure Panel Survey (MEPS); in Justification for Budget Estimates for Appropriations Committees, Fiscal Year 2000. Rockville, Agency for Health Care Research and Quality, 1999. http://www.ahrg.gov/ about/cj2000/cjmeps00.htm (accessed July $18,2006)$.
28 US Department of Health and Human Services, Centers for Disease Control and Prevention, National Center Health Statistics, Division of Data Services: 'Ambulatory Health Care Data'. National Ambulatory Medical Care (NAMCS). Hyattsville, National Center for Health Statistics, US Public Health Service, 2001.

29 Rogers E: Diffusion of Innovations, ed 5. New York, Free Press, 2003.

30 Khoury MJ: Genetics and genomics in practice: the continuum from genetic disease to genetic information in health and disease. Genet Med 2003;5:261-268.

31 Rich EC, Burke W, Heaton CJ, Haga S, Pinsky L, Short MP, Acheson L: Reconsidering the family history in primary care. J Gen Intern Med 2004;19:273-280.

32 Rogers JC, Cohn P: Impact of a screening family genogram on first encounters in primary care. Fam Pract 1987;4:291-301.

33 Yarnall KS, Pollak KI, Ostbye T, Krause KM, Michener JL: Primary care: is there enough time for prevention? Am J Public Health 2003;93:635-641.

34 Qureshi, N, Bethea J, Modell B, Brennan P, Papageorgiou A, Raeburn S, Hapgood R, Modell M: Collecting genetic information in primary care: evaluating a new family history tool. Fam Pract 2005;22:663-669.

35 Taylor AL, Ziesche S, Yancy C, Carson P, D'Agostino R Jr, Ferdinand K, Taylor M, Adams K, Sabolinski M, Worcel M, Cohn JN; African-American Heart Failure Trial Investigators: Combination of isosorbide dinatrate and hydralazine in blacks with heart failure. N Engl J Med 2004;351:2049-2057.

36 Ridker PM, Cook NR, Lee IM, Gordon D, Gaziano JM, Manson JE, Hennekens CH, Buring JE: A randomized trial of low-dose aspirin in the primary prevention of cardiovascular disease in women. $\mathrm{N}$ Engl J Med 2005;432:1293-1304. 